\title{
Las edades del celibato: madurar con, por y en Cristo. Estudios recientes sobre la teología del celibato sacerdotal
}

\author{
The Ages of Celibacy: Maturing through Christ, \\ with Him, and in Him. Recent Views on the Theology \\ of Priestly Celibacy
}

Laurent TouZE

Pontificia Università della Santa Croce. Facoltà di Teologia

Roma. Italia

ID ORCID 0000-0001-8252-3785

touze@pusc.it

Resumen: Este artículo pretende presentar los principales resultados de la investigación teológica sobre el celibato eclesiástico en los últimos diezquince años. Profundiza específicamente en los estudios recientes sobre el principal motivo que el magisterio de la I glesia y la doctrina teológica reconocen a día de hoy al celibato, lo que se llama el motivo nupcial. También se estudiarán las eventuales repercusiones vitales de estos estudios, especialmente los que tratan sobre la espiritualidad sacerdotal.

Palabras clave: Celibato sacerdotal, Sacerdocio ministerial, Espiritualidad sacerdotal, Sacerdotes casados, Eucaristía.
Abstract: : This paper attempts to present the main results of theological research on ecclesiastical celibacy in the last ten to fifteen years. It especially studies recent developments of the main motive for celibacy proposed today by the Magisterium and theology, namely, the so-called spousal motive. The possible vital consequences of this research, particularly on priestly spirituality, will also be considered.

Keywords: Priestly Celibacy, Ministerial Priesthood, Priestly Spirituality, Married Priest, Eucharist. 


\section{INTRODUCCIÓN}

E n 2015, una carta sobre el celibato sacerdotal, escrita por un sacerdote francés desde Madagascar, dio mucho que hablar, especialmente en las redes sociales ${ }^{1}$. El autor reflexionaba sobre el momento en el que, varios años después de ordenarse sacerdote, había alcanzado un entendimiento más profundo del sentido del celibato al escuchar a un enfermo de SIDA agonizante decirle que se sentía acogido por sus atenciones porque sabía que venían de un corazón célibe, en el que ningún afecto conyugal competía con la atención bic et nunc a un moribundo. Esta experiencia -y el eco que suscitó-, recuerda hasta qué punto el sacerdote célibe está llamado a madurar en su entrega y a redescubrirla en todas las etapas de su vida, de la misma manera que un esposo fiel redescubre su vocación al matrimonio a lo largo de las diversas etapas de su propia vida y de la de su cónyuge.

Esta maduración tiene, evidentemente, más de una dimensión, especialmente una dimensión psicológica que este artículo no abordará directamen$t^{2}$. Nos detendremos sobre todo en lo que la teología, el conocimiento y la reflexión aportan a este crecimiento a lo largo del tiempo. Es posible que el razonamiento y la meditación ponderada de la verdad sobre el sacramento del orden no sean los factores más importantes para gozar de una vida célibe feliz y fecunda, pero ciertamente contribuyen a ello.

A este fin, este artículo examinará las reflexiones teológicas recientes sobre el celibato (especialmente en los últimos diez o quince años), aparecidas en las publicaciones que conozco pero teniendo también en cuenta las opiniones convergentes que he escuchado sobre este tema con ocasión de viajes un poco por todo el mundo o en la internacional Roma ${ }^{3}$. Se constatará que, a

${ }^{1}$ Ver GobilliarD, E., http://www.cathedraledupuy.org/vie-de-la-cathedrale/actualites/le-celibatest-un-dur-combat-c2019est-aussi-un-beau-combat (5 de octubre de 2015), última consulta el 14 de febrero de 2018. El autor de la carta, que hoy es obispo auxiliar de Lyon, reprodujo el texto en: Fournal de Tanjomoha, Nouan-Le-Fuzelier: Éditions des Béatitudes, 2016.

2 Sobre este punto, conviene leer el artículo de Wenceslao Vial en este mismo número de Scripta Theologica 50 (2018) 139-166.

3 Me permito citar escritos previos míos sobre este mismo tema: Célibat sacerdotal et théologie nuptiale de l'ordre, Roma: Edizioni Università della Santa Croce, 2002; L'avenir du célibat sacerdotal et sa logique sacramentelle, París: Parole et Silence-Lethielleux, 2009; «La liberté, articulation entre le dogme et la spiritualité. L'exemple du célibat sacerdotal», Annales Theologici 24 (2010) 81-126; «Le célibat sacerdotal, l'Eucharistie et l'Église», en SIRET, V. (ed.), Le célibat sacerdotal. Fondements, joies, défis. Colloque à Ars, 24-25-26 janvier 2011, París: Parole et Silence, 2011, 135-143; «ll celibato è vincolato al sacramento dell'ordine? Per una teologia spirituale del celibato», en TOUze, L. y ARROYO, M. (eds.), Il celibato sacerdotale: teologia e vita, Atti del XIV Convegno della Facoltà di Teologia della Pon- 
fin de cuentas, no hay muchas novedades, lo que hace que éste sea un momento adecuado para reflexionar, asimilar y crecer.

Abordaremos el tema en dos fases: en primer lugar estudiaremos las consecuencias teológicas de la investigación actual sobre la historia del celibato y sobre su vigencia en la Iglesia; y a continuación exploraremos los estudios en profundidad que se han realizado sobre el principal motivo que el Magisterio de la Iglesia y la doctrina teológica reconocen a día de hoy al celibato, lo que se llama el motivo nupcial.

\section{INFORMACIONES PARA LA REFLEXIÓN}

El primer punto que tendremos en cuenta aquí es la ausencia de novedades en lo que se refiere a la historia del celibato sacerdotal. En los años 1980 y 1990 hubo dos décadas de estudios innovadores en este tema que ofrecieron una nueva perspectiva sobre el celibato durante los primeros siglos de historia de la Iglesia ${ }^{4}$. Sus principales contribuciones se pueden resumir en dos puntos. En primer lugar: los clérigos mayores, obispos, sacerdotes y diáconos de los primeros siglos o bien eran solteros o bien, si estaban casados, practicaban la continencia después de su ordenación. Las primeras leyes canónicas explícitas, del siglo IV, fueron una simple consignación por escrito de costumbres teniendo fuerza de ley. En segundo lugar, el abandono de esta tradición original se produjo a partir de la celebración del Concilio oriental Trulano (o Concilio Quinisexto) en 691, y dicho abandono no tuvo equivalente en las leyes de la iglesia occidental, la cual mantenía con el celibato una postura basada en la tradición anterior de la continencia. El Concilio Quinixexto suprimió la continencia absoluta para sacerdotes y diáconos (si bien no para los obispos) que no debían observarla más que antes de celebrar los santos misterios (esta norma de abstinencia temporal ya no se observa hoy en día). A esto hay que añadir el redescubirimiento, hará treinta o cuarenta años, de la exégesis patrística

\footnotetext{
tificia Università della Santa Croce, Roma: Edusc, 2012, 63-84; «Il ministero ordinato e il celibato sacerdotale: una rilettura teologica», en PiLlon, F. (ed.), Prete oggi: pastore e sposo della Chiesa, immagine viva e trasparente di Cristo sacerdote, Cantalupa (Turín): Effatà Editrice, 2015, 11-28.

${ }^{4}$ Ver especialmente: CochINI, C., Les origines apostoliques du célibat sacerdotal, Genève: Ad Solem, $2^{\mathrm{a}}$ ed., 2006 (1 ${ }^{\mathrm{a}}$ ed., 1981); ChOLIJ, R., Clerical Celibacy in East and West, Leominster: Fowler Wright, 1988; STICKLER, A. M., «El celibato eclesiástico. Su historia y sus fundamentos teológicos», Scrripta Theologica 26 (1994) 13-78; HeID, S., Zölibat in der früben Kirche. Die Anfänge einer Enthaltsamkeitspflicht für Kleriker in Ost und West, Paderborn: Schöningh, 1997.
} 
de unius uxoris vir, la fórmula aplicada por las epístolas pastorales a los obispos, sacerdotes y diáconos, y que a veces se invoca como un argumento escriturístico en favor del matrimonio del clero. No obstante, la interpretación del texto en la época patrística (especialmente en los escritos de Orígenes, Eusebio de Cesarea, San Ambrosio, San Siricio, San Epifanio de Salamina, San Juan Crisóstomo, San Inocencio I, San Jerónimo, Teodoreto de Ciro, San Isidoro de Sevilla), era que la monogamia del candidato a las órdenes era prueba de su capacidad de vivir en la ley de la continencia a partir del momento de su ordenación ${ }^{5}$.

Como ya se ha afirmado, no hay novedades en los estudios históricos recientes: ciertamente, se siguen produciendo escritos sobre el celibato del clero vivido -o no vivido- a lo largo del tiempo, especialmente a partir de métodos como los de la historia de la sexualidad ${ }^{6}$ o del género ${ }^{7}$. Pero, aunque los puntos de vista sean más o menos originales, los hechos observados son, en todo caso, siempre los mismos, ya se han analizado con anterioridad, y el conocimiento de los dos puntos de la nueva perspectiva, que hemos resumido en el párrafo anterior, no progresa. Me ha sorprendido constatar que clérigos cultos, que profesaban gratitud al Señor por el don del celibato, desconocen con frecuencia los resultados de estos estudios. Sin duda, dichas investigaciones han recibido críticas, quizá distorsionadas por cierta oposición a la disciplina del celibato, pero nunca se han esgrimido contra ellas, en mi opinión, argumentos científicos convincentes ${ }^{8}$. Las dos perspectivas existentes, la que supone un origen apostólico

${ }^{5}$ Ver Touze, L., L'avenir du célibat sacerdotal et sa logique sacramentelle, 128-129.

${ }^{6}$ En la línea de análisis de Michel Foucault y su historia de la sexualidad.

${ }^{7}$ Por ejemplo, Thibodeaux, J. D., The Manly Priest: Clerical Celibacy, Masculinity, and Reform in England and Normandy, 1066-1300, Filadelfia, PA: University of Pennsylvania Press, 2015.

${ }^{8}$ Ver por ejemplo Touze, L., L'avenir du célibat sacerdotal et sa logique sacramentelle, 20-22. Me gustaría hacer un comentario sobre un libro aún reciente, Collins, R. F., Accompanied by a Believing Wife: Ministry and Celibacy in the Earliest Christian Communities, Collegeville, MN: Liturgical Press, 2013. Este libro propone replantear de forma radical los resultados propuestos sobre todo por Stickler, Cochini o Heid al negar su compatibilidad con el Nuevo Testamento e ilustra el interés y los límites de determinados métodos exegéticos. Por ejemplo, los textos judíos y romanos contemporáneos a la redacción de los libros del Nuevo Testamento muestran una preferencia clara por el matrimonio, pero esto no se traslada necesariamente a Jesús o a Pablo. Podemos recordar una vez más, como hace Collins, que los exégetas proponen más de una interpretación para la expresión «hombre de una sola mujer» que aparece en las epístolas pastorales, pero posiblemente no convencerá más que a los ya convencidos, cuando afirma que este ápax en todo el griego conocido significaría simplemente que un sacerdote debería estar casado. Collins menciona en general determinadas ideas propuestas anteriormente que no parecen invalidar los estudios de Stickler, Cochini o Heid, quienes, al hacer referencia al Nuevo Testamento, hacen uso de una interpretación compatible con las acepciones patrísticas. 
del celibato y la continencia y la que propone una aparición posterior, en torno al siglo IV, cuentan con sus argumentos y sus defensores. Aunque estoy convencido de la primera, quizá por razón de un mínimo de objetividad científica se debería reconocer a las dos el mismo nivel de plausibilidad. En los dos casos, «todo es (...) cuestión de interpretación, de lectura, de búsqueda de coherencia y de una visión global de la historia ${ }^{9} \gg$. No es necesario hablar siempre de ostracismo o censura con respecto a los autores que mantienen el primer punto de vista, pero lo cierto es que se les aprecia más cuanto más se les conoce.

Tras estas consideraciones históricas, pasamos a la actualidad, empezando por las tensiones eclesiales (entre grupos) y eclesiológicas (discordancias teológicas) que dan origen al debate existente sobre el celibato sacerdotal. Hablar de celibato sacerdotal en una asamblea de sacerdotes que reuniera a clérigos regulares y seculares podría suscitar tensiones que no se deben ignorar, y que ponen de manifiesto las implicaciones, también teológicas, de esta cuestión. Algunos clérigos seculares tienen la impresión de que la vida consagrada pretende resolver su crisis de identidad reclamando el monopolio del celibato. Muchos consagrados están a la búsqueda del mínimo común denominador que les distingue de otras vocaciones eclesiales. La referencia a la profesión de los consejos evangélicos, si bien en teoría les caracteriza ${ }^{10}$, no convence a todos ${ }^{11}$. Desde una perspectiva fenomenológica, lo que uniría a todos sería el celibato por el reino y la vida en común ${ }^{12}$. El sacerdote secular célibe que a menudo vive con otros hermanos y trata de constituir una fraternidad con ellos corre el riesgo de sentirse integrado en la vida consagrada sin su consentimiento, en una especie de Anschluss espiritual. Utilizo deliberadamente términos conflic-

9 FaIvre, A., «Recension de Cochini, C., "Les origines apostoliques du célibat sacerdotal”», Revue d'Histoire et de Philosophie Religieuses 63 (1983) 471-473, aquí 472.

${ }^{10}$ Ver, por ejemplo, Touze, L., «Consejos evangélicos», en Otaduy, J., Viana, A. y Sedano, J. (eds.), Diccionario general de derecho canónico, Cizur Menor-Pamplona: Aranzadi-Universidad de Navarra, 2012, vol. II, 630-635.

${ }^{11}$ Ver, por ejemplo, MATURA, T., Le radicalisme évangélique aux sources de la vie chrétienne, París: Cerf, 1980; Tillard, J. M. R., «Consigli evangelici», en Pelliccia, G. y Rocca, G. (eds.), Dizionario degli Istituti di Perfezione, II, Roma, 1975, 1630-1685; CIARDI, F., «Criticità di alcune teologie della vita consacrata e ricerca di nuove teologie», en BEVILACQUA, M. (ed.), Teologia e teologie della Vita Consacrata. Simposio, Roma, 13-14 maggio 2015, Roma: Istituto di Teologia della Vita Consacrata «Claretianum», 2016, 165-190.

${ }^{12}$ Ver por ejemplo los argumentos de J. P. Longeat, en aquel momento Abad de Ligugé y presidente de la Conferencia de religiosos y religiosas de Francia (CORREF) entre 2010 y 2016. «Lo que tenemos en común es que seguimos a Cristo desde el celibato y la comunidad». https://fr.zenit. org/articles/jeunes-derangez-les-adultes-et-choisissez-le-christ-par-le-p-longeat/ (3 de diciembre de 2014), última consulta el 14 de febrero de 2018. 
tivos hasta la caricatura porque he visto más de una vez cómo debates que se planteaban de manera pacífica de repente se volvían tensos al abordar estos temas. Especialmente, creo, porque los seculares tienen la impresión de que los religiosos reclaman el celibato para ellos solos porque se consideran todavía en una posición de superioridad en términos eclesiológicos, y por lo tanto, verían con buenos ojos el matrimonio de los sacerdotes seculares, según una concepción doblemente negativa (y muchas veces meramente implícita) tanto de la secularidad como del matrimonio ${ }^{13}$. Con el fin de apaciguar las tensiones reivindicativas y particularistas entre grupos eclesiásticos, una de las vías más oportunas será sin duda la espiritualidad de la comunión que proponía Juan Pablo II hace casi veinte años, al principio del milenio: una espiritualidad que debería ayudar a todos los agentes eclesiásticos a rechazar «las tentaciones egoístas que nos tienden continuamente trampas y que provocan competitividad, carrierismo, desconfianza y envidias» ${ }^{14}$. Al valorar las diferencias legítimas que existen en el seno de la Iglesia, se evita transformarla en un laboratorio pastoral en el que se experimentaría con personas y con vocaciones.

Recientemente, se han dado una serie de novedades entre las que vale la pena citar una medida establecida por la Santa Sede y que a primera vista podría parecer puramente disciplinaria y sin grandes implicaciones teológicas. Se trata del decreto dictado en 2008 por la Congregación para los Obispos en relación a la pérdida del estado clerical de Fernando Lugo, antiguo obispo que acababa de ser elegido presidente de Paraguay: Lugo había recibido también una dispensa de sus votos religiosos, de la obligación del celibato y de otras obligaciones asociadas a la condición clerical ${ }^{15}$. Dentro de estas medidas,

${ }^{13}$ Sor Carmen Sammut, superiora general de las Hermanas Misioneras de Nuestra Señora de África y presidente de la UISG, Unión Internacional de Superioras Generales, respondía así recientemente a un periodista que le preguntaba si el Papa tenía que suprimir el celibato sacerdotal: «Per i religiosi no: la loro dedizione agli altri dev'essere totale. Ma il celibato sacerdotale è solo una legge della Chiesa latina»: Il Corriere della Sera (3 de marzo de 2018), 29.

${ }^{14}$ Carta apostólica Novo millennio ineunte (6 de enero de 2001), n. 43. Se parece quizá al tono de determinados discursos del Papa Francisco a los clérigos.

${ }^{15} \mathrm{Ver}$ «Decreto de Pérdida del Estado Clerical de S.E. Mons. Fernando Armindo Lugo Méndez (30 de julio de 2008)»: http://es.missionerh.com/content/view/2268/91/, última consulta el 14 de febrero de 2018, en el que cabe destacar: «Su Santidad Benedicto XVI ha concedido para él la pérdida del estado clerical, con la consiguiente pérdida de los derechos inherentes al mismo, dispensándolo al mismo tiempo de los votos religiosos hechos en la Sociedad del Verbo Divino, de la obligación del celibato (ver CIC can. 291) y de las demás obligaciones que el estado clerical comporta (ver CIC can. 292)». El decreto fue publicado por la nunciatura de Paraguay. La suspensión a divinis de Lugo ya era efectiva desde el 20 de enero de 2007. 
la más inesperada es la dispensa de la obligación del celibato para un obispo. Se trata de un caso inédito en la historia de la Iglesia: nunca antes alguien que hubiera recibido la plenitud del sacramento del orden había recibido autorización para contraer matrimonio. Al constatar esta coherencia a lo largo de dos milenios, creí oportuno escribir hace una década: «La Iglesia muestra una firmeza inalterable cuando es consciente de su deber de proteger un legado del cual es servidora. Así, creo que se puede hablar del celibato y continencia del obispo como una tradición en el sentido clásico del término ${ }^{16} \gg$. El hecho de que un bautizado revestido con el carácter episcopal no haya nunca contraído matrimonio sacramental me parecía indicar una posible tradición, que arrojaría luz sobre el celibato sacerdotal, y, por elevación hacia lo alto del sacramento del orden, haría especialmente conveniente la continencia sacerdotal. La decisión tomada para el caso Lugo no invalida completamente esta argumentación por diversas razones. La jurisprudencia del caso Lugo refleja claramente una tendencia reciente de la teología del orden, la de la conciencia de su unidad ${ }^{17}$. Si la Iglesia acepta a diáconos y sacerdotes casados que hacen uso del matrimonio, quizás podría hacer lo mismo con los obispos. No obstante, se trata de una medida puntual (una tantum) y única en dos mil años, que además, no se ha materializado, puesto que hasta donde yo sé, Lugo no ha contraído matrimonio. Además, uno de los grandes teólogos recientes del concepto de tradición, Yves Congar, escribió que «no se debe hacer una distinción demasiado radical y carente de matices entre un orden de cosas divinamente determinadas y una disciplina que constituiría el ámbito de un derecho puramente positivo y eclesiástico ${ }^{18} \gg$. Por supuesto que existen matices, nacidos de tradiciones eclesiásticas, entre ellos el celibato sacerdotal, que sería «algo (...) más profundo que un derecho puramente positivo y cambiante, algo menos absoluto que las realidades que el Señor mismo ha determinado con precisión. (...) En este sentido, una derogación en una cuestión como ésta no es absolutamente imposible, pero es, y debe ser, excepcional. Cuando se produce, hace referencia a la regla mediante una aplicación de este poder, siempre vivo dentro de la Iglesia, que se ejerció en el origen por la determinación normativa que corresponda ${ }^{19} \gg$. Una comprensión más precisa de la re-

\footnotetext{
${ }^{16}$ Ver Touze, L., L'avenir du célibat sacerdotal et sa logique sacramentelle, 27-28.

${ }^{17}$ Sobre la unidad de los tres niveles de orden, ver por ejemplo: GOYRET, P., Chiamati, consacrati, inviati. Il sacramento dell'ordine, Ciudad del Vaticano: Libreria Editrice Vaticana, 2003, 120.

${ }_{18}$ Congar, Y., Sainte Église, París: Cerf, 1964, 295.

${ }^{19}$ Ibid., 297.
} 
lación entre la disciplina y la doctrina serviría para arrojar más luz sobre la cuestión ${ }^{20}$.

Otra medida disciplinar reciente parece también debilitar la importancia que la Sede apostólica reconoce al celibato. Se trata del replanteamiento que se hizo en 2014 de las medidas pontificias que prohibían la presencia de un clero oriental casado en territorios en los que la mayoría de los católicos siguen la tradición romana. Se temía, según parece, el escándalo de los fieles que no estaban acostumbrados a la presencia de las esposas de sacerdotes católicos. La magnitud de los desplazamientos de población, particularmente los que afectan de forma especialmente cruel a los cristianos orientales, ha hecho que este principio legislativo se acabara modificando ${ }^{21}$. En este contexto, que demuestra que es necesario un mayor conocimiento por una y otra parte, y especialmente un mayor conocimiento del Oriente cristiano por parte los occidentales, los miembros de la iglesia latina no deberían tampoco idealizar la vida de los sacerdotes casados ${ }^{22}$. Hace unos años, al referirse a la población sacerdotal actual en la Grecia ortodoxa (formada por 11.000 hombres de los cuales 3.000 estaban casados), el presidente de una asociación griega de sacerdotes observaba que el número de estos últimos experimentaba un descenso constante ${ }^{23}$. Eso sucedía particularmente por una causa: mientras que, en las sociedades tradicionales, contraer matrimonio con un sacerdote era (y es todavía, en las comunidades culturalmente más inmovilistas) un honor y un ascenso social, cada vez menos mujeres emancipadas desean llevar la vida de esposas de un sacerdote. De la misma forma, se ha observado que los múltiples divorcios sacerdotales (dado que las familias de los sacerdotes se ven afectadas por las mismas dificultades que las demás) plantean nuevos problemas.

No obstante, el decreto relativo a Lugo o el levantamiento de las restricciones a la distribución de clérigos orientales casados, no han modificado las líneas generales del discurso papal sobre el celibato sacerdotal. Éste no es «un

${ }^{20}$ Ver, por ejemplo, RIVOIRE, R. M., La valeur doctrinale de la discipline canonique: l'engagement du Magistère dans les lois et coutumes de l'Église, Roma: Edusc, 2016.

21 Congregación para las Iglesias Orientales, Documento Pontificia precepta de clero uxorato orientali (14 de junio de 2014), Acta Apostolice Sedis 106 (2014) 496-499.

${ }^{22}$ En la misma línea de ideas, pero esta vez pensando quizá en los pastores de las comunidades nacidas de la Reforma, Pablo VI escribió: «No se puede creer simplemente que la abolición del celibato eclesiástico, por sí mismo, haría aumentar de forma notable el número de vocaciones: la experiencia actual de las Iglesias y comunidades eclesiásticas en la que los ministros ordenados pueden contraer matrimonio parece demostrar lo contrario» (Enc. Sacerdotalis caelibatus, n. 49).

${ }^{23}$ Ver http://www.zenit.org/english/archive/0002/ZE000228, última consulta el 8 de enero de 2006. 
dogma de fe» (Papa Francisco, Conferencia de prensa durante el vuelo de regreso de Tierra Santa, 26 de mayo de 2014), pero los textos normativos recientes publicados por las congregaciones vaticanas manifiestan en todos los casos una clara preferencia por el celibato ${ }^{24}$.

Mientras tanto, más que esperar del magisterio de la Iglesia la comodidad intelectual de nuevos textos parenéticos, hermosos pero no siempre aplicados, el sacerdote que considera el celibato como un don debería quizás preguntarse, en primer lugar, cómo se ha servido, personalmente, de los documentos ya publicados, y especialmente de lo que es que sin duda su mensaje principal, sobre la dimensión nupcial del celibato, que se encuentre en el corazón de la articulación entre el sacramento del orden y la libertad del ministro.

\section{PRofundización DEL MOTIVO NUPCiAL DEL CELIBato}

Si observamos a vista de pájaro la perspectiva histórica de los textos eclesiásticos sobre el celibato sacerdotal, se constata rápidamente una tendencia que se ha afianzado recientemente, a partir del Concilio Vaticano II. Simplificando un poco las tendencias para resumirlas mejor, podríamos afirmar que la mayor parte de los textos precedentes son, o bien medidas canónicas que reafirman una disciplina, o bien exhortaciones desde perspectivas más teológicas, pero que se suelen articular alrededor de la pureza ritual, la intuición de la existencia de un vínculo entre la continencia y el culto, que se suele describir con connotaciones peyorativas para la sexualidad incluso dentro del matrimonio, un discurso que hoy, por suerte, sería impresentable en una Iglesia sensible al matrimonio como vocación a la santidad ${ }^{25}$.

Esto cambió a partir del decreto Presbyterorum ordinis [en lo sucesivo, $\mathrm{PO}]$, y la motivación teológica del celibato se fue concentrando en un motivo

\footnotetext{
${ }^{24}$ Ver, por ejemplo, CONGREgaCión PARA EL CleRO, Ratio fundamentalis institutionis sacerdotalis «El don de la vocación presbiteral» (8 de diciembre de 2016), nn. 84.e; 95; 192; y sobre todo el n. 110 por el contenido teológico, que remite a Presbyterorum ordinis, n. 16 y Pastores dabo vobis, n. 29, de los que hablaremos más adelante. No obstante, hay que tener en cuenta que determinados colaboradores del Papa Francisco han anunciado que la ordenación de viri probati se podría estudiar en la asamblea sinodal sobre la Amazonia que se celebrará en octubre de 2019. Ver, por ejemplo, TosatTi, M., «Viri probati, l'accelerazione della Chiesa tedesca», http://www.lanuovabq.it/it/ (15 de noviembre de 2017), última consulta el 14 de febrero de 2018.

25 Ver, por ejemplo, Verkamp, B., «Cultic Purity and the Law of Celibacy», Review for Religious 30 (1971) 199-217.
} 
nupcial, por utilizar el adjetivo habitual y aparentemente antinómico para describir un estado no matrimonial. La encíclica Sacerdotalis caelibatus (24 de junio de 1967) del beato Pablo VI lo presenta de la siguiente manera: «"Apresado por Cristo Jesús" (Fil 3,12) hasta el abandono total de sí mismo en él, el sacerdote se configura más perfectamente a Cristo también en el amor, con que el eterno sacerdote ha amado a su cuerpo, la Iglesia, ofreciéndose a sí mismo todo por ella, para hacer de ella una esposa gloriosa, santa e inmaculada. Efectivamente, la virginidad consagrada de los sagrados ministros manifiesta el amor virginal de Cristo a su Iglesia y la virginal y sobrenatural fecundidad de esta unión» (n. 26) ${ }^{26}$. Por su configuración especifica con Cristo que se entregó en el altar de la cruz por la Iglesia, el sacerdote es llamado a participar libremente en esta ofrenda entregando también su cuerpo, en conformidad y continuidad con las palabras que pronuncia cada día al celebrar la Santa Misa: «Esto es mi cuerpo». Al celebrar los santos misterios, aprende lo que significa verdaderamente la entrega total de sí mismo, teniendo ante él el memorial de la pasión y la resurrección de Cristo, y debe asimismo aprender a trasladar esta lógica a su existencia cotidiana y al servicio de los fieles concretos que se le han confiado por su prelado. Aquí entra en juego la caridad pastoral, uno de los conceptos fundamentales de Presbyterorum ordinis. Esta «fluye sobre todo del Sacrificio Eucarístico, que se manifiesta por ello como centro y raíz de toda la vida del presbítero, de suerte que lo que se efectúa en el altar lo procure reproducir en sí el alma del sacerdote» (PO, n. 14). Para que el ministro aprenda a pasar, gracias a su libertad, del sacramento del orden a su vida, la Iglesia le propone optar por el celibato como una adaptación a la forma de vida adoptada por el único Sacerdote de la nueva alianza, y como una participación en su ofrenda en favor de su Esposa, la Iglesia. «El celibato lanza un primer punto, público, jurídico, que el sacerdote asume porque la ley eclesiástica se lo ofrece, un puente (...) entre la consagración y la misión, y apela a la libertad del ministro para construir nuevos puentes por los que transferir la lógica del orden, la lógica del don y la lógica del servicio a su propia existencia. El celibato se convierte así en una llama que acompaña al sacerdote a lo largo de su vida y le recuerda en todas las etapas de su camino que debe inmolarse por el servicio concreto a la Iglesia y a las almas ${ }^{27} \gg$.

\footnotetext{
${ }^{26}$ Sobre este texto de Pablo VI, ver ARANDA, A., «La encíclica "Sacerdotalis caelibatus", cincuenta años después», Scripta Theologica 49 (2017) 403-425.

27 Touze, L., La liberté, articulation entre le dogme et la spiritualité. L'exemple du célibat sacerdotal, 124.
} 
Si desde el Concilio Vaticano II hasta hoy ha existido evolución y se ha ido precisando progresivamente el sentido exacto de este motivo nupcial, ha sido en un sentido cada vez más eucarístico ${ }^{28}$. El ministro aprende la lógica de su celibato al celebrar la Eucaristía, y la refuerza con cada celebración. Pablo VI también escribió: «actuando en la persona de Cristo, el sacerdote se une más íntimamente a la ofrenda, poniendo sobre el altar su vida entera, que lleva las señales del holocausto» (Enc. Sacerdotalis caelibatus, n. 29). La vocación del sacerdote le lleva a ofrecer toda su existencia, como sin duda todos los bautizados, pero de una forma específica, como corresponde a la función específica que cumple en la liturgia. «La conformidad al misterio eucarístico (con el que el sacerdote tiene un vínculo específico) confiere al motivo cristológico (del celibato) (...) una dimensión propiamente ministerial» ${ }^{29}$. En la segunda asamblea ordinaria del sínodo de los obispos (1971), tras largos debates, los Padres sinodales concluyeron: «Mediante el celibato, el sacerdote, siguiendo a su Señor, manifiesta con más plenitud su disponibilidad y, comprometiéndose en el camino de la cruz con el gozo pascual, desea ardientemente consumirse en una ofrenda eucarística ${ }^{30} \gg$. Es precisamente mediante su celibato como el sacerdote aprende concretamente la «lógica eucarística de la existencia cristiana ${ }^{31} \gg$. La exhortación apostólica Sacramentum caritatis de Benedicto XVI (22 de febrero de 2007) sitúa más claramente la entrega de sí mismo del sacerdote célibe en un marco eucarístico. Esta exhortación retoma la argumentación de una asamblea sinodal sobre la Eucaristía, un tema que $a$ priori no tendría por qué implicar que se abordara el tema del celibato de los ministros. No obstante, en el movimiento de las intuiciones precedentes del magisterio, los Padres sinodales y el que hoy es papa emérito consideraron oportuno precisar en este texto enteramente consagrado a la Eucaristía que: «El celibato sacerdotal (...) representa una especial configuración con el estilo de vida del propio Cristo. Dicha opción es ante todo esponsal; es una identificación con el corazón de Cristo Esposo que da la vida por su Esposa» ( $\mathrm{Sa}$ -

${ }^{28} \mathrm{La}$ «simbolica nuziale [...] emerge in misura crescente nei testi recenti del Magistero ecclesiale»: Ouellet, M., Celibato e legame nuziale di Cristo alla Chiesa, Città del Vaticano: Libreria Editrice Vaticana, 2016, 47.

${ }^{29}$ OCÁRIZ, F., «Sulla relazione tra sacerdozio e celibato», Sacrum Ministerium 17 (2011) 27-35, aquí 35.

30 SínOdo de lOS OBISPOS, Documento sobre el sacerdocio ministerial Ultimis temporibus (30 de noviembre de 1971), parte II, I, 4.

31 Sobre esta expresión, ver BENEDICTO XVI, Exhortación apostólica Sacramentum caritatis, toda la tercera parte y especialmente el número 80 sobre el sacerdocio. 
cramentum caritatis, n. 24). El vínculo entre la continencia y la celebración, concebido de forma intuitiva a lo largo de los siglos pero mal transmitido por el vocabulario de la pureza ritual, encuentra en el motivo nupcial y eucarístico del celibato una formulación más adecuada y más exacta ${ }^{32}$. El celibato «corresponde a la ofrenda eucarística del Señor que, por amor, ofreció su cuerpo de una vez por todas hasta el punto extremo de la distribución sacramental, y que reclama de la persona llamada una respuesta del mismo orden, es decir, total, irrevocable y sin condiciones ${ }^{33} \gg$.

En los últimos años ha habido una interesante multiplicación de estudios sobre estos puntos. Se pueden encontrar tanto obras más generales sobre el celibato $^{34}$ como estudios más particulares sobre la naturaleza de la nupcialidad eucarística del ministerio, especialmente aplicado a la disciplina del celibato ${ }^{35}$.

32 «Tale modo di istruire il nesso celibato/Eucaristia risulta decisamente più pertinente di quello [...] legato al tema della purità cultuale»: CisLAGHI, G., «Celibi per il ministero ordinato, la tradizione della Chiesa latina», Scuola Cattolica 136 (2008) 345-367, aquí 357.

33 Ouellet, M., Celibato e legame nuziale di Cristo alla Chiesa, 50.

${ }^{34}$ Por ejemplo: La Soujeole, B. D. DE, Prêtre du Seigneur dans son Église: quelques requêtes actuelles de spiritualité sacerdotale, París: Parole et Silence, 2009, que ofrece un marco claro, especialmente sobre el celibato, 126-129; BERTRAND, M., Le prêtre de demain sera-t-il célibataire?, París: Éditions de l'Emmanuel, 2011, que cita encuestas sociológicas y permanece atento al eco que suscitan los debates teológicos en la opinión pública; CAVADINI, J. C. (ed.), The Charism of Priestly Celibacy: Biblical, Theological, and Pastoral Reflections, Notre Dame, IN: Ave Maria Press, 2012, sobre diversos aspectos del celibato, como resume adecuadamente el título; KENNEDY, A. (ed.), Celibacy and the Priesthood: Divine Gift and Cultural Anomaly, Boston, MA: Saint Botolph Press, 2012, donde el cardenal Ouellet ya proponía un discurso en primer lugar escatológico, 1-39, que se desarrolla en su obra de 2016; CATTANEO, A. (ed.), Prêtres mariés? 30 questions brûlantes sur le célibat, Montreal: Éditions des Oliviers, 2015, que se ha publicado también al menos en inglés, italiano, castellano y alemán; Selin, G., Priestly Celibacy: Theological Foundations, Washington D.C.: Catholic University of America Press, 2016, especialmente 167-178 sobre la dimensión eucarística. Sobre el vínculo entre el celibato y la paternidad espiritual del sacerdote, a partir de la antropología tomista, ver GRIFFIN, C. H., Supernatural Fatherhood through Priestly Celibacy: Fulfillment in Masculinity. A Thomistic Study, Roma: Edusc, 2011. Para una reflexión más amplia sobre la representación de Cristo Cabeza de la Iglesia en el ministerio: DANTAS, J. P. de M., In persona Christi capitis. Il ministro ordinato come rappresentante di Cristo capo della Chiesa nella discussione teologica da Pio XII fino ad oggi, Siena: Cantagalli, 2010. Se han anunciado nuevas publicaciones, por ejemplo: DeVIlle, A., (ed.), Married Catholic Priests. History, Theology, and Pastoral Challenges, Notre Dame, IN: University of Notre Dame Press.

35 Especialmente, en orden cronológico: Brown, C. J., The Development of the Concept of the Spousal Relationship between Bishop and Local Church in the West to the Ninth Century, Roma: Pontificium Athenaeum S. Anselmi de Urbe, 2008: el índice general de la tesis es muy interesante, el extracto publicado extremadamente bien argumentado (sobre el siglo IX), pero, que yo sepa, el texto integral del estudio todavía no se ha publicado; Cozzens, A. H., Imago vivens Iesu Christi Sponsi Ecclesiae. The Priest as a Living Image of Jesus Christ the Bridegroom of the Church through the Evangelical Counsels, Saint Paul, MI, 2008, tesis que en su título indica la perspectiva que adopta, desarrollada especialmente a partir del pensamiento de Hans Urs von Balthasar; WOJTAL, T., Come 
Está claro que la praxis concreta de los sacerdotes no ha respondido suficientemente a este desarrollo excepcional del magisterio y a estas profundizaciones teológicas. Esta falta de respuesta no sólo se ha manifestado en los escándalos en los que se han visto envueltos miembros del clero últimamente, sino también más generalmente porque «el elemento más característico de todo el magisterio conciliar y, por decir así, su finalidad última» ${ }^{36}$, que es la llamada universal a la santidad ${ }^{37}$, todavía no constituye el eje de la vida cristiana de los fieles, estén ordenados o no. En este contexto, se entiende la referencia a Cristo en el título de este artículo: para crecer (y no sólo envejecer) en el celibato, los sacerdotes pueden tratar de abrir sus existencias particulares a Dios todopoderoso volviéndose a Jesucristo, presente en la vida de la Iglesia y de sus ministros especialmente en la Eucaristía.

Solamente «cuando los sacerdotes, a través de la oración, entran más profundamente en el misterio de Cristo» (PO, n. 14) pueden volver a aprender en el altar los secretos de la caridad pastoral rogando al Señor que se digne iniciarlos más profundamente en el «misterio de la novedad de Cristo» (Enc. Sacerdotalis caelibatus, n. 23). Los sacerdotes son diariamente llamados a vivir esta situación en el momento de la celebración de la eucaristía.

Este retorno diario a la lógica de la entrega de sí, análoga a la que viven los cónyuges, que a través de la Eucaristía renuevan las gracias sacramentales de su matrimonio ${ }^{38}$, toma todos los diversos acentos de la celebración. En su obra reciente sobre el celibato y el vínculo nupcial entre Cristo y su Iglesia, Marc Ouellet insiste especialmente en la dimensión escatológica ${ }^{39}$. La Iglesia

Cristo sposo della Chiesa: aspetti dogmatici del celibato spirituale, Siena: Cantagalli, 2015, sobre todo la $5^{\text {a }}$ parte sobre el dogma, 253-348; Pilloni, F. (ed.), Prete oggi: pastore e sposo della Chiesa, immagine viva e trasparente di Cristo sacerdote, Cantalupa (Torino): Effatà, 2015, centrado en la espiritualidad; Ciarrocchi, A. M., Sponsus Ecclesiae, sicut Christus: sobre el simbolismo nupcial del sacerdote desde Hugo de San Victor hasta santo Tomás de Aquino, Siena: Cantagalli, 2016, por ejemplo sobre Santo Tomás de Aquino, 281-369: el cuerpo forma parte de la significación visible del carácter sacerdotal, que constituye una potencia espiritual enraizada en el alma del sacerdote pero que abraza su cuerpo: su voz, su masculinidad, etc.; acerca de la conveniencia del celibato, 360366; Ouellet, M., Celibato e legame nuziale di Cristo alla Chiesa, Città del Vaticano: Libreria Editrice Vaticana, 2016, que desarrolla la articulación entre la dimensión escatológica de la Eucaristía y el celibato, estado escatológico especialmente adecuado para el celebrante de la Misa.

36 Beato Pablo VI, Motu Proprio Sanctitas clarior (19 de marzo de 1969).

37 Bosch, V., «El valor programático de la santidad. Una clave hermenéutica del Concilio Vaticano II, a 40 años de distancia», Annales Theologici 19 (2005) 171-211; IDEM, Llamados a ser santos: bistoria contemporánea de una doctrina, Madrid: Palabra, 2008.

${ }^{38}$ Ver Ouellet, M., Mystère et sacrement de l'amour, París: Cerf, 2014.

39 El ya citado Ouellet, M., Celibato e legame nuziale di Cristo alla Chiesa, 2016. 
y la teología insisten siempre más en este punto: la Eucaristía hace presente el éskhaton y conviene que la celebre un ministro que adopte una forma de vida escatológica ${ }^{40}$. Si todas las formas de celibato por el reino de Dios son nupcias aplazadas ${ }^{41}$ y tienen por tanto una dimensión escatológica, existe una adecuación escatológica especial del celibato ministerial, una opción visible en el celebrante, que es una persona pública que actúa delante de la comunidad. Se trataba de una intuición presente en el concilio ${ }^{42}$ y desarrollada por Benedicto XVI. Para que los ministros puedan decir de verdad: «mi cuerpo», «mi sangre», Cristo les atrae hacia su realidad de Resucitado: «El celibato es una anticipación. Trascendemos y nos adelantamos a nuestro tiempo, tirando así de nosotros mismos y de nuestro tiempo hacia el mundo de la resurrección, hacia la novedad de Cristo, hacia la vida nueva y verdadera. El celibato es pues una anticipación que la gracia del Señor hace posible, que nos atrae hacia él, hacia el mundo de la resurrección. (...) El sentido del celibato como anticipación del futuro es precisamente (...) ensanchar el mundo, mostrar la realidad del futuro que debemos vivir como algo ya presente» (Conclusión del año sacerdotal. Vigilia de oración, 10 de junio de 2010).

Esta dimensión escatológica no es la única de la que se alimenta el sacerdote en toda celebración de la Eucaristía: hay otras, ofrecidas a la libertad de cada uno y a las diferentes fases de su vida. A todos se propone la misma melodía, pero, como en los órganos con múltiples registros, cada ministro puede, según le inspire el Espíritu Santo, seleccionar juegos distintos. Un sacerdote puede ser más sensible al hecho de que la Eucaristía construye bic et nunc la comunidad que celebra con él, y que esta presencia, física o intencional, le incita al servicio y a la entrega de sí. Sabe que es célibe para amar, y que en cada Misa vuelve a la escuela del amor con las fuerzas que recibe en el sacramento. Que la Eucaristía sea el centro significa, para todos, y por lo tanto también para el ministro, vivir de forma concreta el misterio de la entrega que se celebra en el altar. Al pronunciar las palabras de la consagración, el ministro

40 Ver ibid., 37-40.

${ }^{41}$ Ver VALLIN, P., «"Voici l'Époux qui vient" (Mt 25,6): la formalité théologique du lien conjugal en christianisme comme vérité de l'Eschaton», Revue de Droit Canonique 66 (2016) 25-44.

${ }^{42}$ Los sacerdotes célibes «de esta forma, pues, manifiestan delante de los hombres que quieren dedicarse al ministerio que se les ha confiado, es decir, de desposar a los fieles con un solo varón, y de presentarlos a Cristo como una virgen casta y con ello evocan el misterioso matrimonio establecido por Dios, que ha de manifestarse plenamente en el futuro, por el que la Iglesia tiene a Cristo como Esposo único» (PO, n. 16). 
está particularmente invitado a ofrecerse por la comunidad con la que celebra $^{43}$. La entrega de su celibato se inscribe en esta dinámica de amor a Jesucristo: «Al seguir el ejemplo de Cristo, el ministro ofrece su cuerpo para la misión, para la salvación del mundo ${ }^{44} \gg$, especialmente para los hombres y las mujeres especialmente confiados a los cuidados ministeriales del sacerdote y respecto a los cuales ejerce la caridad pastoral.

\section{CONCLUSIÓN}

En los años de 1960-1970, un determinado número de obras defendían el matrimonio del clero planteándolo como una especie de promoción del laicado. La participación de los fieles no ordenados en las acciones sagradas sería más intensa porque se sentirían representados por la familia del ministro: el sacerdocio común estaría valorizado por el vínculo de la esposa y los hijos del sacerdote con el ministerio de su esposo y padre ${ }^{45}$. Estas ideas, en último término muy clericales, según las cuales el máximo al que podría aspirar un laico sería a orbitar alrededor del sacerdote, ya no se proponen hoy, al menos de manera directa. No obstante, no hay duda que no se ha aprehendido suficientemente la raíz sacramental de la llamada universal a la santidad, el vínculo que une cada vocación con los sacramentos que están asociados a ella. En el caso del sacerdocio se refiere a los sacramentos del orden y la Eucaristía, y su puerta común, el bautismo: el sacerdote está, por el sacramento del orden, señalado como una persona pública a los ojos de la comunidad, y su principal función es servir a esa comunidad celebrando los santos misterios ante ella y por ella. Siempre en virtud de su cualidad de persona pública, su celibato le permite asumir estatuto visible y conocido de vida eucarística, de don de sí que pasa por la entrega del cuerpo.

El hecho de que el ministro contrajera matrimonio parecería dar otro tipo de testimonio público, vivido de acuerdo con el sacrificio nupcial de Cristo y gracias a él. Los fieles casados (los sacerdotes casados en este caso) viven, ellos también, del pan de la Eucaristía, y su matrimonio también es un estatuto socialmente reconocible. Por lo tanto, podríamos imaginar que convivieran

${ }^{43}$ Ver Greshake, G., Priester sein in dieser Zeit, Friburgo-Basilea-Viena: Edusc, 2000, 286-287.

${ }^{44}$ OCÁRIZ, F., «Sulla relazione tra sacerdozio e celibato», 27.

45 Por ejemplo: Bergeron, P., Pour le mariage du prêtre: le couple sacerdotal, Montreal: Le Jour, 1970; Hamburger, G. (pseudónimo de Schermann, R.), Katholische Priesterehe oder der Tod eines Tabus?, Reinbek: Rowohlt, 1968. 
habitualmente dos tipos de ministros, casados o solteros, de forma habitual y no excepcional (como sucede hoy, con algunos casos puntuales en la Iglesia latina y una minoría de sacerdotes en las Iglesias católicas orientales) ${ }^{46}$. De hecho, seguro que existen ministros casados ejemplares, tanto en Oriente como en Occidente ${ }^{47}$. No obstante, me parece (y es también una de las líneas de profundización desarrolladas estos últimos años) que la reflexión sobre el motivo nupcial muestra hasta qué punto el celibato es especialmente adecuado para el ministerio y para su carácter público. Por la forma en la que se visibiliza y se lee, el celibato asume una función de signo, que debe ser fácilmente identificable como tal. Esto supone al menos dos cosas: desde un punto de vista canónico, que los sacerdotes casados sigan siendo una mera excepción, de modo que se siga percibiendo el testimonio del celibato; y desde un punto de vista espiritual, que este testimonio sea realmente de santidad, de integridad y de entrega (al contrario de lo que muchos hombres y mujeres han visto últimamente). San Juan Pablo II consideraba que difundir la llamada universal a la santidad, colaborar con Dios para extenderla y hacerla viva, concreta y práctica, sigue siendo «la principal orientación que ha sido determinada para los hijos y las hijas de la Iglesia en este Concilio [Vaticano II] cuyo fin es la renovación evangélica de la vida cristiana ${ }^{48} \gg$. Quien comparta este análisis del Santo Pontífice polaco, estará especialmente atento a conservar los signos que propagan esta llamada. Dios y los hombres habrían podido imaginar una Iglesia en la que los sacerdotes casados fueran mayoría. Pero con esta configuración se habría corrido el riesgo de perder uno de los grandes mensajes de la teología posconciliar del celibato, es decir, la adecuación libre del sujeto de los sacramentos a las gracias que ha recibido. Dado que el sacerdote sabe que los sacramentos, y muy especialmente la Eucaristía, cambian todo, escucha la voz de Dios que proclama: «He aquí que yo hago nuevas todas las cosas» (Ap 21,5). Y cree que su debilidad puede ser transfigurada por el poder de Dios. Una Iglesia indiferente al estado matrimonial de sus clérigos pondría quizás

\footnotetext{
${ }^{46}$ Podría ser útil recordar que la Iglesia católica cuenta con alrededor de 400.000 sacerdotes, de los cuales sólo están casados unos 5.000, es decir un poco más del 1\%.

$47 \mathrm{El}$ interesante estudio de MERCIER, J., Célibat des prêtres. La discipline de l'Église doit-elle changer?, París: Desclée de Brouwer, 2014 recoge varios hermosos testimonios de sacerdotes de la iglesia latina casados, antiguos pastores protestantes o anglicanos, y un análisis de sus declaraciones, en las páginas 201-248.

48 San Juan Pablo II, Exhortación apostólica postsinodal Christifideles laici (30 de diciembre de 1988), n. 16.
} 
de manifiesto una fe debilitada en la virtud de los sacramentos, especialmente de la Eucaristía. Habría que preguntarse además si la Iglesia ha asimilado realmente los importantes mensajes eucarísticos que ha escuchado al final de pontificado de Juan Pablo II y posteriormente en el de Benedicto XVI. En este sentido, teniendo en cuenta también las novedades propuestas por los estudios recientes sobre el celibato, un sacerdote que desea -vir desideriorum - crecer en el amor por su vocación, al servicio de Dios y de sus hermanos, tratará de volver hacia la Misa en tanto que centro y raíz para vivir de ella siempre más. 


\section{Bibliografía}

ARANDA, A., «La encíclica "Sacerdotalis caelibatus", cincuenta años después», Scripta Theologica 49 (2017) 403-425.

Bergeron, P., Pour le mariage du prêtre: le couple sacerdotal, Montreal: Le Jour, 1970.

Bertrand, M., Le prêtre de demain sera-t-il célibataire?, París: Éditions de l'Emmanuel, 2011.

Bosch, V., «El valor programático de la santidad. Una clave hermenéutica del Concilio Vaticano II, a 40 años de distancia», Annales Theologici 19 (2005) 171-211.

Bosch, V., Llamados a ser santos: historia contemporánea de una doctrina, Madrid: Palabra, 2008.

Brown, C. J., The Development of the Concept of the Spousal Relationship between Bishop and Local Church in the West to the Ninth Century, Roma: Pontificium Athenaeum S. Anselmi de Urbe, 2008.

Cattaneo, A. (ed.), Prêtres mariés? 30 questions brûlantes sur le célibat, Montreal: Éditions des Oliviers, 2015.

Cavadini, J. C. (ed.), The Charism of Priestly Celibacy: Biblical, Theological, and Pastoral Reflections, Notre Dame, IN: Ave Maria Press, 2012.

CholI, R., Clerical Celibacy in East and West, Leominster: Fowler Wright, 1988.

CIARDI, F., «Criticità di alcune teologie della vita consacrata e ricerca di nuove teologie», en BevilaCQua, M. (ed.), Teologia e teologie della Vita Consacrata. Simposio, Roma, 13-14 maggio 2015, Roma: Istituto di Teologia della Vita Consacrata «Claretianum», 2016, 165-190.

Ciarrocchi, A. M., Sponsus Ecclesiae, sicut Christus: sobre el simbolismo nupcial del sacerdote desde Hugo de San Víctor hasta santo Tomás de Aquino, Siena: Cantagalli, 2016.

Cislaghi, G., «Celibi per il ministero ordinato, la tradizione della Chiesa latina», Scuola Cattolica 136 (2008) 345-367.

CochINI, C., Les origines apostoliques du célibat sacerdotal, Genève: Ad Solem, $2^{\mathrm{a}}$ ed., 2006 ( $1^{\mathrm{a}}$ ed., 1981).

Collins, R. F., Accompanied by a Believing Wife: Ministry and Celibacy in the Earliest Christian Communities, Collegeville, MN: Liturgical Press, 2013.

Congar, Y., Sainte Église, París: Cerf, 1964. 
Cozzens, A. H., Imago vivens Iesu Christi Sponsi Ecclesiae. The Priest as a Living Image of Fesus Christ the Bridegroom of the Church through the Evangelical Counsels, Saint Paul, MI, 2008.

DANTAS, J. P. de M., In persona Christi capitis. Il ministro ordinato come rappresentante di Cristo capo della Chiesa nella discussione teologica da Pio XII fino ad oggi, Siena: Cantagalli, 2010.

FaIvRE, A., «Recension de Cochini, C., "Les origines apostoliques du célibat sacerdotal"», Revue d'Histoire et de Philosophie Religieuses 63 (1983) 471-473.

GOBILLIARD, E., http://www.cathedraledupuy.org/vie-de-la-cathedrale/actualites/le-celibat-est-un-dur-combat-c2019est-aussi-un-beau-combat $(5$ de octubre de 2015), consultado el 14 de febrero de 2018.

Gobilliard, E., fournal de Tanjomoha, Nouan-Le-Fuzelier: Éditions des Béatitudes, 2016.

GOYRET, P., Chiamati, consacrati, inviati. Il sacramento dell'ordine, Ciudad del Vaticano: Libreria Editrice Vaticana, 2003.

GreshaKe, G., Priester sein in dieser Zeit, Friburgo-Basilea-Viena: Herder, 2000.

GRIFFIN, C. H., Supernatural Fatherhood through Priestly Celibacy: Fulfillment in Masculinity. A Thomistic Study, Roma: Edusc, 2011.

Hamburger, G. (pseudónimo de Schermann, R.), Katholische Priesterehe oder der Tod eines Tabus?, Reinbek: Rowohlt, 1968.

HeID, S., Zölibat in der frïhen Kirche. Die Anfänge einer Enthaltsamkeitspflicht fuir Kleriker in Ost und West, Paderborn: Schöningh, 1997.

Kennedy, A. (ed.), Celibacy and the Priesthood: Divine Gift and Cultural Anomaly, Boston, MA: Saint Botolph Press, 2012.

La Soujeole, B. D. DE, Prêtre du Seigneur dans son Église: quelques requêtes actuelles de spiritualité sacerdotale, París: Parole et Silence, 2009.

LONGEAT, J. P., https://fr.zenit.org/articles/jeunes-derangez-les-adultes-etchoisissez-le-christ-par-le-p-longeat/ (3 de diciembre de 2014), última consulta el 14 de febrero de 2018.

Matura, T., Le radicalisme évangélique aux sources de la vie chrétienne, París: Cerf, 1980.

Mercier, J., Célibat des prêtres. La discipline de l'Église doit-elle changer?, París: Desclée de Brouwer, 2014.

OCÁRIZ, F., «Sulla relazione tra sacerdozio e celibato», Sacrum Ministerium 17 (2011) 27-35.

Ouellet, M., Mystère et sacrement de l'amour, París: Cerf, 2014. 
Ouellet, M., Celibato e legame nuziale di Cristo alla Chiesa, Ciudad del Vaticano: Libreria Editrice Vaticana, 2016.

Pilloni, F. (ed.), Prete oggi: pastore e sposo della Chiesa, immagine viva e trasparente di Cristo sacerdote, Cantalupa (Torino): Effatà, 2015.

RIVOIRE, R. M., La valeur doctrinale de la discipline canonique: l'engagement du Magistère dans les lois et coutumes de l'Église, Roma: Edusc, 2016.

SElin, G., Priestly Celibacy: Theological Foundations, Washington D.C.: Catholic University of America Press, 2016.

STICKLER, A. M., «El celibato eclesiástico. Su historia y sus fundamentos teológicos», Scrripta Theologica 26 (1994) 13-78.

Thibodeaux, J. D., The Manly Priest: Clerical Celibacy, Masculinity, and Reform in England and Normandy, 1066-1300, Filadelfia, PA: University of Pennsylvania Press, 2015.

Tillard, J. M. R., «Consigli evangelici», en Pelliccia, G. y Rocca, G. (eds.), Dizionario degli Istituti di Perfezione, II, Roma, 1975, 1630-1685.

Touze, L., Célibat sacerdotal et théologie nuptiale de l'ordre, Roma: Edizioni Università della Santa Croce, 2002.

Touze, L., L'avenir du célibat sacerdotal et sa logique sacramentelle, París: Parole et Silence-Lethielleux, 2009.

Touze, L., «La liberté, articulation entre le dogme et la spiritualité. L'exemple du célibat sacerdotal», Annales Theologici 24 (2010) 81-126.

Touze, L., «Le célibat sacerdotal, l'Eucharistie et l'Église», en SireT, V. (ed.), Le célibat sacerdotal. Fondements, joies, défis. Colloque à Ars, 24-25-26 janvier 2011, París: Parole et Silence, 2011, 135-143.

Touze, L., «Il celibato è vincolato al sacramento dell'ordine? Per una teologia spirituale del celibato», en Touze, L. y ARroyo, M. (eds.), Il celibato sacerdotale: teologia e vita, Atti del XIV Convegno della Facoltà di Teologia della Pontificia Università della Santa Croce, Roma: Edusc, 2012, 63-84.

Touze, L., «Consejos evangélicos», en Otaduy, J., Viana, A. y Sedano, J. (eds.), Diccionario general de derecho canónico, Cizur Menor-Pamplona: Aranzadi-Universidad de Navarra, 2012, vol. II, 630-635.

TouzE, L., «Il ministero ordinato e il celibato sacerdotale: una rilettura teologica», en Pilloni, F. (ed.), Prete oggi: pastore e sposo della Chiesa, immagine viva e trasparente di Cristo sacerdote, Cantalupa (Torino): Effatà Editrice, 2015, 11-28. 
VALLIN, P., «"Voici l'Époux qui vient” (Mt 25,6): la formalité théologique du lien conjugal en christianisme comme vérité de l'Eschaton», Revue de Droit Canonique 66 (2016) 25-44.

Verkamp, B., «Cultic Purity and the Law of Celibacy», Review for Religious 30 (1971) 199-217.

VIAL, W., «Psicología y celibato», Scripta Theologica 50 (2018) 139-166.

Wojtal, T., Come Cristo sposo della Chiesa: aspetti dogmatici del celibato spirituale, Siena: Cantagalli, 2015. 
